\title{
Comparative studies on the structure, biological activity and molecular mechanisms of polysaccharides from Boletus aereus (BA-T) and Pleurotus cornucopiae (PC-1)
}

\author{
Xiang DING ${ }^{1,2 \#}$, Xian TANG ${ }^{1 \#}$, Yiling $\mathrm{HOU}^{1,3,4 *}$
}

\begin{abstract}
In this study, two new polysaccharides were extracted from the fruiting bodies of Boletus aereus and Pleurotus cornucopiae, respectively. The results of structure identification showed that BA-T was composed of xylose residues, glucose residues and galactose residues, and the ratio is 3:6:6. The BA-T takes 1,6-glucose and 1,6-galactose as skeletons, extends a branched chain from galactose 2-O to connect 1,4-xylose, and connects $\beta$-4-glucose terminal monosaccharide to xylose. PC- 1 was composed of of xylose, glucose and galactose in the ratio of 2:8:2 and takes 1,6-glucose as skeletons, extends a branched chain from galactose 4 -O to connect $(1 \rightarrow 4,, 6)-\alpha-D-G l c p$ and $(1 \rightarrow 2,6)-\alpha$-D-galactose, and $\rightarrow 4)-\beta-D-G l c p$ and $\rightarrow 1)-\alpha-D-X y l p$ as terminal group. The results of immunoactivity showed that BA-T and PC-1 have the proliferation activity of B cells, T cells and RAW264.7 cells in vitro, and the effect of $\mathrm{BA}-\mathrm{T}$ on the proliferation of $\mathrm{T}$ cells was the greatest. The results of RNA-sequencing showed that the protein synthesis and metabolism of $\mathrm{T}$ cells are more vigorous under the stimulation of BA-T, and oxidative phosphorylation is the main energy source in the process of $\mathrm{T}$ cell proliferation.
\end{abstract}

Keywords: Boletus aereus; Pleurotus cornucopiae; structure identification; immune activity; molecular mechanism.

Practical Application: Fungal polysaccharides can be used as candidate drugs for immunomodulation and antitumor.

\section{Introduction}

In recent years, natural polysaccharides have received increasing attention in the biomedical field, because they not only have significant anti-tumor and immunomodulatory activities, but also have low toxic side effects (Valverde et al., 2015). Polysaccharide biology has become a frontier science after nucleic acid and protein. Fungal polysaccharide is a kind of natural macromolecular substance, which usually contains primary, secondary, tertiary and quaternary structures (Meng et al., 2016). The structure of fungal polysaccharide is very complex due to the types of monosaccharide residues, the connection sites and sequence of glycosidic bonds, the branching degree of side chain and the different conformations (Chaturvedi et al., 2018). Since the first confirmation of lentinan's anti-tumor activity in 1968 , fungal polysaccharides have been widely concerned in the fields of health food and biomedicine due to their anti-virus, antioxidation, anti-tumor, immune regulation and other biological activities, as well as their safety and non toxicity (Chihara et al., 1987). Craterellus cornucopioides polysaccharide can induce RAW264.7 cell activation and significantly improve its proliferation activity in a certain concentration range (Guo et al., 2019). Tricholoma matsutake polysaccharide can not only promote the proliferation of lymphocytes and macrophages in vitro, enhance the phagocytic capacity of macrophages, but also promote macrophages to secrete cytokines (TNF)- $\alpha$ (Byeon et al., 2009).
Boletus aereus and Pleurotus cornucopiae are two kinds of rare edible and medicinal fungus with high medicinal value . In recent years, studies have shown that polysaccharide from Boletus aereus and Pleurotus cornucopiae have some interesting biological activities, such as bacteriostasis, antioxidation, et al. (Hagiwara et al., 2005; Wang et al., 2013; Wu et al., 2014; Minato et al., 2017; Lee et al., 2017; Zhang et al., 2014). However, there are some differences in the structure of polysaccharides from different regions, and there is no report on the study of the polysaccharides of Boletus aereus and Pleurotus cornucopiae from Litang county of Sichuan Province. (China). In the present study, two novel water-soluble polysaccharide BA-T and PC-1 were extracted, isolated and purified from the fruiting bodies of Boletus aereus and Pleurotus cornucopiae, respectively. The chemical structure and immune activity of the two polysaccharides were first studied and compared to help determine the molecular mechanism underlying the biological activity of polysaccharide BA-T and PC-1.

\section{Materials and methods}

\subsection{Experimental materials and chemicals}

Boletus aereus and Pleurotus cornucopiae were collected from Qingiiang county of Sichuan Province. (China). The ethanol

${ }^{1}$ Key Laboratory of Southwest China Wildlife Resources Conservation, College of Life Sciences, China West Normal University, Nanchong, Sichuan, China

${ }^{2}$ College of Environmental Science and Engineering, China West Normal University, Nanchong, Sichuan, China

${ }^{3}$ Irradiation Preservation Technology Key Laboratory of Sichuan Province, Sichuan Institute of Atomic Energy, Sichuan, Chengdu, China

${ }^{4}$ Departmental and Municipal Co-construction of Crops Genetic Improvement of Hill Land Key Laboratory of Sichuan Province, Nanchong, Sichuan, China

"Xiang Ding and Xian Tang are co-first authors.

*Corresponding author: starthlh@126.com 
was purchased from Swancor Shanghai Fine Chemical Co., Ltd. (Shanghai, China). Trifluoroacetic acid (TFA), standard monosaccharide and dextran of different molecular weight were purchased from Tianjin Kermel Chemical Reagent Co., Ltd. (Tianjin, China). DEAE-cellulose (DE-52) was purchased from Beijing Solarbio Science \& Technology Co., Ltd. (Beijing, China). Cell counting kit (CCK-8 cell counting kit) was purchased from Dojindo Molecular Technologies, Inc. (Shanghai, China). PBS buffer, lipopolysaccharide (LPS), 0.5\% Trypsin-EDTA, neutral red and dimethyl sulfoxide (DMSO) were purchased from Sigma-Aldrich Inc. (Missouri, USA). RPMI1640 medium (phenol red free) and fetal bovine serum (FBS) were purchased from Gibco Inc. (New York, USA). All analytical reagents were of analytical grade.

\subsection{Extraction and purification of polysaccharides}

Dry fruiting bodies powder (400 g) was boiled in water for 3 times (6 h for each) (Hu et al., 2021; Liu \& Li, 2021). The supernatant was concentrated after centrifugation. Three times volume of $95 \%$ ethanol were added in the supernatant to precipitate crude polysaccharides. The crude polysaccharides were purified by DEAE cellulose (DE-52) column and dialysis (7000 Da, Biosharp), drying in vacuum freeze-drying machine (ALPHA2-4LD plus, Christ). The final polysaccharide from Boletus aereus and Pleurotus cornucopiae were named BA-T and $\mathrm{PC}-1$, respectively.

\subsection{Determination of the molecular weight}

The molecular weight of polysaccharide was determined via high-performance gel permeation chromatography (HPGPC). A total of $10 \mathrm{mg}$ polysaccharide was weighted, dissolved in $1 \mathrm{~mL}$ distilled water and filtered $(0.22 \mu \mathrm{M}$ pore). The measured data was analyzed via Empower Pro GPC software (version B.01.02; Agilent Technologies Inc., USA) and known dextran standards were used as references.

\subsection{Fourier Transform Infrared spectrometer (FT-IR) analysis}

A total of $5 \mathrm{mg}$ polysaccharide was weighted, then ground and mixed with dry $\mathrm{KBr}$. The data was collected via the mixture scanning within $4000 \mathrm{~cm}^{-1}$ to $400 \mathrm{~cm}^{-1}$ in the fourier transform infrared spectrometer (Nicolet 5700, Thermo Scientific) (Li et al., 2021).

\subsection{Monosaccharide composition analysis}

The monosaccharide composition of polysaccharide was analyzed by high performance liquid chromatography (HPLC) (Agilent 1100, USA), respectively (Aydogancoskun et al., 2020; Karaoğlan \& Cabaroğlu, 2020). A total of $20 \mathrm{mg}$ polysaccharide was dissolved in $5 \mathrm{~mL}$ trifluoroacetic acid (TFA) solution $(2 \mathrm{~mol} / \mathrm{L}$ ) and hydrolyzed for $6 \mathrm{~h}\left(100^{\circ} \mathrm{C}\right)$. The supernatant was dried and washed with distilled water to remove residual TFA (repeated 3 times). Operating conditions were detector: RID detector; injection volume: $10 \mu \mathrm{L}$; column temperature: $35^{\circ} \mathrm{C}$. Known monosaccharide samples were used as standards (Li et al., 2020; Zheng et al., 2020).

\subsection{Methylation analysis and GC-MS}

Methyl iodide reagent was used to obtain methylated polysaccharide. The dry methylated product was dissolved in $2 \mathrm{M}$ TFA, then hydrolyzed for $6 \mathrm{~h}\left(100^{\circ} \mathrm{C}\right)$. Silane reagent was was used to prepare derivatized product detected by GC-MS (Agilent 7890A, USA). The initial temperature set at $80^{\circ} \mathrm{C}$ and maintained for $3 \mathrm{~min}$, with a linear increase to $200^{\circ} \mathrm{C}$ at a rate of $10^{\circ} \mathrm{C} / \mathrm{min}$, then maintaining at $200^{\circ} \mathrm{C}$ for $10 \mathrm{~min}$ (Ismail et al., 2020; Sun et al., 2020; Yang et al., 2020).

\subsection{Nuclear Magnetic Resonance (NMR) assay}

A total of $50 \mathrm{mg}$ polysaccharide was dissolved in $500 \mu \mathrm{l}$ $\mathrm{D}_{2} \mathrm{O}$. The ${ }^{1} \mathrm{H}$ NMR spectra, ${ }^{13} \mathrm{C}$ NMR spectra, ${ }^{1} \mathrm{H}-{ }^{1} \mathrm{H}$ COSY spectra, HMQC spectra and HMBC spectra were analyzed by the Varian Unity INOVA 400/45 (Varian Medical Systems, USA) and internal standard was tetramethylsilane (He et al., 2020; Kim et al., 2021).

\subsection{Cell lines and reagents}

Macrophages RAW264.7 cell line, B cell line, T cell line and S180 cell line (sarcoma cell) were purchased from the cell bank of the Typical Culture Preservation Committee of the Chinese Academy of Science (Shanghai, China). All cells were cultivated in RPMI 1640 medium with $10 \% \mathrm{FBS}, 1 \%$ penicillin $(100 \mathrm{IU} / \mathrm{mL})$ and streptomycin $(100 \mathrm{mg} / \mathrm{L})$ at $37^{\circ} \mathrm{C}$ with $5 \%$ $\mathrm{CO}_{2}$. All cell lines came from mice.

\subsection{T cells, B cells and RAW264.7 cells proliferation assay}

Pharmacological evaluation of polysaccharide on T cells, B cells and RAW264.7 cells proliferation was examined via CCK-8 method. Cells $\left(1 \times 10^{5}\right.$ cells $\left./ \mathrm{mL}\right)$ were added to a 96 -well plate $(100 \mu \mathrm{L} /$ well $)$ and incubated for $24 \mathrm{~h}\left(5 \% \mathrm{CO}_{2}, 37^{\circ} \mathrm{C}\right)$. Different concentrations of polysaccharide (final concentration $5,10,20 \mu \mathrm{g} / \mathrm{mL})$ were added to the 96 -well plate $(100 \mu \mathrm{L} /$ well $)$, incubated for $24 \mathrm{~h}$. LPS (final concentration $5 \mu \mathrm{g} / \mathrm{mL}$ ) and the cell culture medium were used as positive control and negative control, respectively. Proliferation assay was analyzed via instructions of CCK-8. The value of optical density (OD) was detected at $450 \mathrm{~nm}$. The way of calculating cell viability was: cell proliferation rate $(\%)=[(\mathrm{As}-\mathrm{Ac}) /(\mathrm{Ac}-\mathrm{Ab})] \times 100 \%$, where $\mathrm{Ac}$ was the absorbance of negative control group, $\mathrm{Ab}$ was the absorbance of blank group, As was the absorbance of experimental groups. The Leica Microsystems inverted fluorescence microscope (DMI4000B, Germany) was used to observe the cell morphology and alterations to cell numbers.

\subsection{Transcriptome sequencing}

The collected cells of control group, LPS group and BA-T group were used to carry out transcriptome assay. The cells, quickly freezed by liquid nitrogen, were sent to Novogene Bioinformatics Technology Co. Ltd, Beijing, China. The remaining tumor tissues were stored at $-80^{\circ} \mathrm{C}$. After the samples were 
quantified, the library was constructed and checked, and subsequently sequenced using an Illumina Hiseq platform. Genes with an adjusted $\mathrm{P}<0.05$ identified by DESeq 2 were classified as differentially expressed. Subsequently, the clusterProfiler $\mathrm{R}$ package was used for Gene Ontology (GO) analysis and Kyoto Encyclopedia of Genes and Genomes (KEGG) pathways analysis. Differentially expressed genes were analyzed using the edgeR program (version 3.11).

\subsection{Statistical analysis}

Data were showed as the mean \pm standard deviation (SD). All statistical comparisons were analyzed using a one-way analysis of variance (ANOVA) test followed by StudentNewmanKeuls test with SPSS 17.0 software. Compared with the blank control group, the significant difference was indicated by ${ }^{*}, P<0.05$, and the extremely significant difference was indicated by ${ }^{\star *}, P<0.01$.

\section{Results and discussion}

\subsection{Elution curve of polysaccharide}

Distilled water, $0.05 \mathrm{~mol} / \mathrm{L}, 0.1 \mathrm{~mol} / \mathrm{L}$ and $0.2 \mathrm{~mol} / \mathrm{L} \mathrm{NaCl}$ were used as eluents to elute polysaccharide from Boletus aereus and Pleurotus cornucopiae, respectively. The elution results of polysaccharide were shown in Figure 1A and 1B. With the increase of $\mathrm{NaCl}$ concentration, there are three and one main elution peaks, respectively. In this study, all neutral polysaccharide eluates in distilled water were collected as the research objects. According to the calculation, the yield of BA-T and PC-1 in the total fruiting body were about $0.4 \%$ and $0.3 \%$, respectively.

\subsection{Molecular weight of polysaccharides}

The molecular weight of polysaccharide was determined by HPGPC. The weight-average molecular weight $(\mathrm{Mw})$ was $14552 \mathrm{Da}$, the peak molecular weight (Mp) was $14395 \mathrm{Da}$, the number-average molecular weight $(\mathrm{Mn})$ was $6957 \mathrm{Da}$ and the polydispersity was 2.09 of polysaccharides BA-T (Figure 1C). The weight-average molecular weight $(\mathrm{Mw})$ was $26606 \mathrm{Da}$, the peak molecular weight $(\mathrm{Mp})$ was $22369 \mathrm{Da}$, the number-average molecular weight $(\mathrm{Mn})$ was $14992 \mathrm{Da}$ and the polydispersity was 1.77 of polysaccharides PC-1(Figure 1D).

\subsection{FT-IR analysis of polysaccharides}

The Fourier transform infrared spectrum of BA-T is shown in Figure 1E. There were typical polysaccharide absorption peaks at $3436 \mathrm{~cm}^{-1}, 2923 \mathrm{~cm}^{-1}$ and $1400-1200 \mathrm{~cm}^{-1}$, and there were no other impurity peak, indicating that the purified BA-T was a kind of polysaccharide. The broad absorption peak at $3436 \mathrm{~cm}^{-1}$ is O-H stretching vibration peak, the absorption peak at $2923 \mathrm{~cm}^{-1}$ is - $\mathrm{CH}_{2}$ stretching vibration peak, the signal at $1635 \mathrm{~cm}^{-1}$ is $\mathrm{C}=\mathrm{O}$ stretching vibration peak, the signal at $1400 \mathrm{~cm}^{-1}$ is C-H in-plane bending vibration peak of - $\mathrm{CHO}$, and the signal at $1081 \mathrm{~cm}^{-1}$ is $\mathrm{C}$-O stretching vibration peak. The absorption peak in the range of $1200-1000 \mathrm{~cm}^{-1}$ is the absorption peak of pyranosyl lactone and hydroxyl, indicating that BA-T has pyranosyl. The absorption peak at $878 \mathrm{~cm}^{-1}$ indicates that BA-T contains $\beta$-pyranose, and the absorption peak at $562 \mathrm{~cm}^{-1}$ indicates that BA-T contains a-configuration. In addition, there was no absorption peak near $1730 \mathrm{~cm}^{-1}$, indicating that BA-T did not contain uronic acid.

The results of PC-1 infrared spectrum were shown in Figure 1F. The broad absorption peak at $3432 \mathrm{~cm}^{-1}$ is O-H stretching vibration peak, the absorption peak at $2924 \mathrm{~cm}^{-1}$ is $-\mathrm{CH}_{2}$ stretching vibration peak, the signal at $1637 \mathrm{~cm}^{-1}$ is $\mathrm{C}=\mathrm{O}$ stretching vibration peak, the signal at $1402 \mathrm{~cm}^{-1}$ is $\mathrm{C}-\mathrm{H}$ in-plane bending vibration peak of - $\mathrm{CHO}$, and the signal at $1086 \mathrm{~cm}^{-1}$ is sugar $\mathrm{C}-\mathrm{O}$ stretching vibration peak. The absorption peak in the range of $1200-1000 \mathrm{~cm}^{-1}$ is the absorption peak of pyranosyl lactone and hydroxyl, indicating that PC-1 has pyranosyl. There is an absorption peak at $877 \mathrm{~cm}^{-1}$, which indicates that PC-1 contains $\beta$-pyranose, and there is a cyclic symmetric vibration peak of $\alpha$ - hexopyranose at $797 \mathrm{~cm}^{-1}$. There is an absorption peak at $557 \mathrm{~cm}^{-1}$, which indicates that PC-1 contains $\alpha$ - configuration. In addition, there is no absorption peak near $1730 \mathrm{~cm}^{-1}$, indicating that PC-1 does not contain uronic acid, neither.

\subsection{Monosaccharide composition analysis of polysaccharides}

The monosaccharide composition and ratio of BA-T were analyzed by HPLC. The retention time of the six standards is as follows: Rha: $4.291 \mathrm{~min}$, Xylose: $4.928 \mathrm{~min}$, Ara: $5.619 \mathrm{~min}$, Mannose: $6.434 \mathrm{~min}$, Glucose (GLC): $6.694 \mathrm{~min}$, Galactose (Gal): $7.236 \mathrm{~min}$. According to the peak time of monosaccharide standard, xylose (Xyl) was estimated at $5.048 \mathrm{~min}$, glucose (Glc) at $6.713 \mathrm{~min}$ and galactose $(\mathrm{Gal})$ at $7.249 \mathrm{~min}$. The peak area ratio of xylose: glucose: galactose is about 1:2:2.

The retention time of the six standards in PC-1 experimentis as follows: Rha: $4.409 \mathrm{~min}$; Xylose: $5.026 \mathrm{~min}$; Arabinose: $5.785 \mathrm{~min}$; Mannose: $6.625 \mathrm{~min}$; Glucose (GLC): $6.932 \mathrm{~min}$; Galactose (Gal): $7.492 \mathrm{~min}$. According to the peak retention time of monosaccharide standard, xylose (Xyl) was estimated at $5.313 \mathrm{~min}$, glucose $(\mathrm{Glc})$ at $6.953 \mathrm{~min}$ and galactose $(\mathrm{Gal})$ at $7.504 \mathrm{~min}$. The peak area ratio of xylose: glucose: galactose is about 1:4:1.

\section{5 ${ }^{1} \mathrm{H}-\mathrm{NMR}$ analysis of polysaccharides}

NMR could provide related hydrogen and carbon signals of different monosaccharides in polysaccharides. The results show that BA-T and PC- 1 both have five anomeric protons signals, which are at $\delta 5.00, \delta 4.95, \delta 4.90, \delta 4.88$ and $\delta 4.42$, respectively, and the integral area ratio is 1: 0.8: 0.21: $0.76: 0.2$, and at $\delta 5.19, \delta 4.95, \delta$ $4.81, \delta 4.62$ and $\delta 4.33$, respectively, and the integral area ratio is $0.8: 1.83: 1.29: 1.03: 0.53$ (Figure $1 \mathrm{G}, \mathrm{H}$ ). There was no signal after chemical shift $\delta 5.40$, indicating that BA-T and PC-1 were composed of pyranose, which was consistent with the results of FT-IR analysis. The signal between $\delta 3.0$ and $\delta 4.2$ is attributed to the hydrogen signal of $\mathrm{C} 2-\mathrm{C} 6$ in the monosaccharide residue.

\section{6 ${ }^{13} \mathrm{C}-\mathrm{NMR}$ analysis of polysaccharides}

The results of ${ }^{13} \mathrm{C}$ NMR spectrum of BA-T and PC-1 show that BA-T and PC-1 both have five anomeric carbon, which are at $\delta 102.44, \delta 102.34, \delta 101.50, \delta 101.35$ and $\delta 97.91$, respectively, and at $\delta 102.65, \delta 101.62, \delta 98.22, \delta 98.59$ and $\delta 98.06$, respectively (Figure 1I, J). There was no signal at $\delta 106-109 \mathrm{ppm}$ and $\delta 82$ - 
A

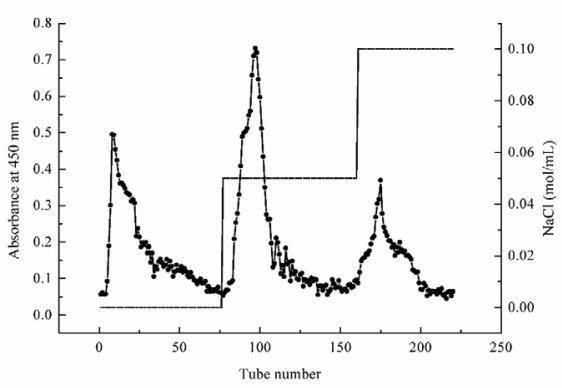

C

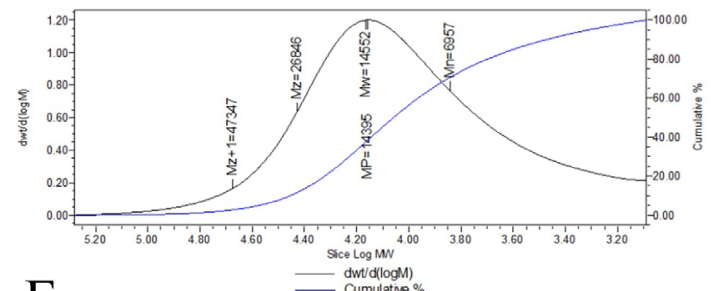

$\mathrm{E}$

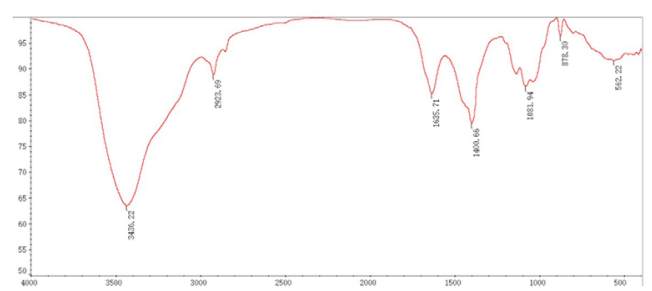

G

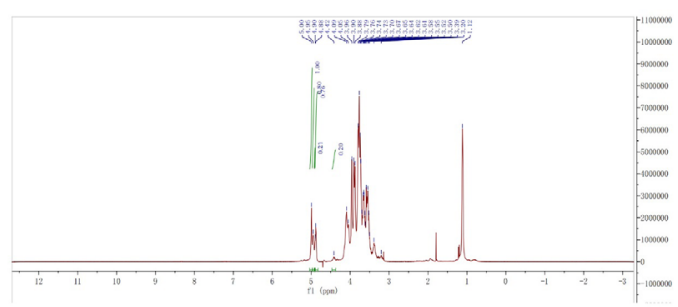

I

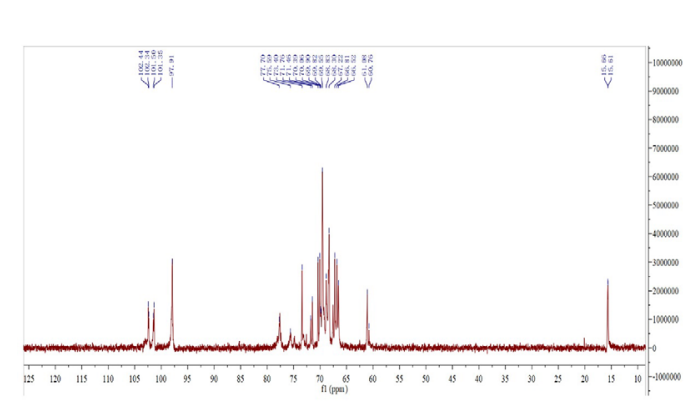

B

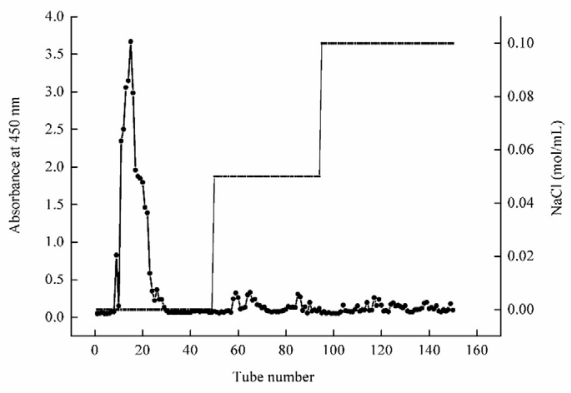

$\mathrm{D}$

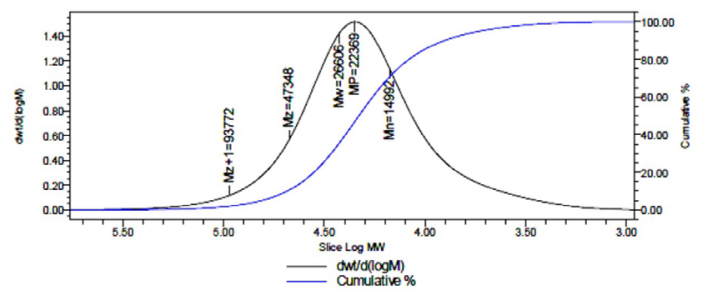

$\mathrm{F}$

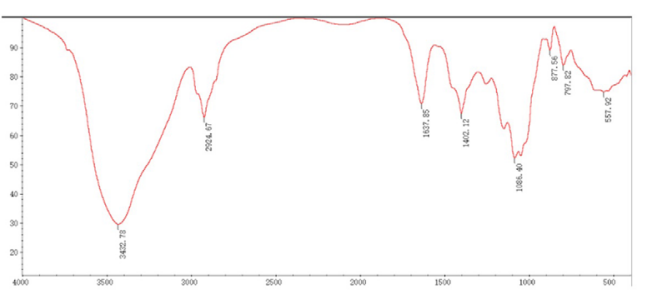

$\mathrm{H}$

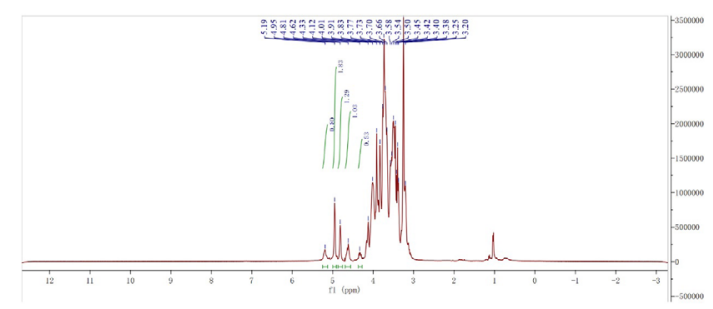

J

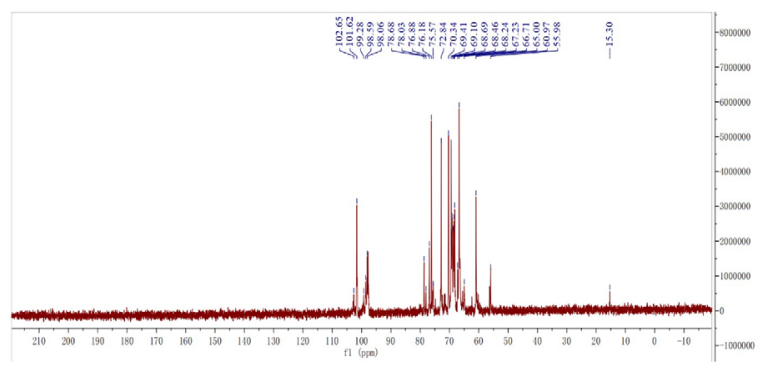

Figure 1. (A) Elution curve of BA-T by column chromatography; (B) Elution curve of PC-1 by column chromatography; (C) The molecular weight of BA-T; (D) The molecular weight of PC-1; (E) The fourier transform infrared spectra of BA-T; (F) The fourier transform infrared spectra of PC-1; (G) The ${ }^{1} \mathrm{H}$ NMR spectra of PC-1; (H) The ${ }^{1} \mathrm{H}$ NMR spectra of BA-T; (I) The ${ }^{13} \mathrm{C}$ NMR spectra of BA-T; (J) The ${ }^{13} \mathrm{C}$ NMR spectra of PC-1.

$84 \mathrm{ppm}$, which indicated that BA-T and PC-1 were composed of pyranose and had no furan ring, which was consistent with the results of ${ }^{1} \mathrm{H}$ NMR analysis. The signal between $\delta 60-78 \mathrm{ppm}$ is attributed to the carbon signal of C2-C6 in sugar residues.

\section{$3.7^{1} \mathrm{H}-{ }^{1} \mathrm{HCOSY}$ analysis of polysaccharides}

Each proton signal of monosaccharides in polysaccharides could be obtained by ${ }^{1} \mathrm{H}-{ }^{1} \mathrm{H}$ COSY spectrum. In the ${ }^{1} \mathrm{H}-{ }^{1} \mathrm{H}$ COSY spectrum of BA-T (Figure $2 \mathrm{~A}$ ), the cross signal A ( $\delta$ 

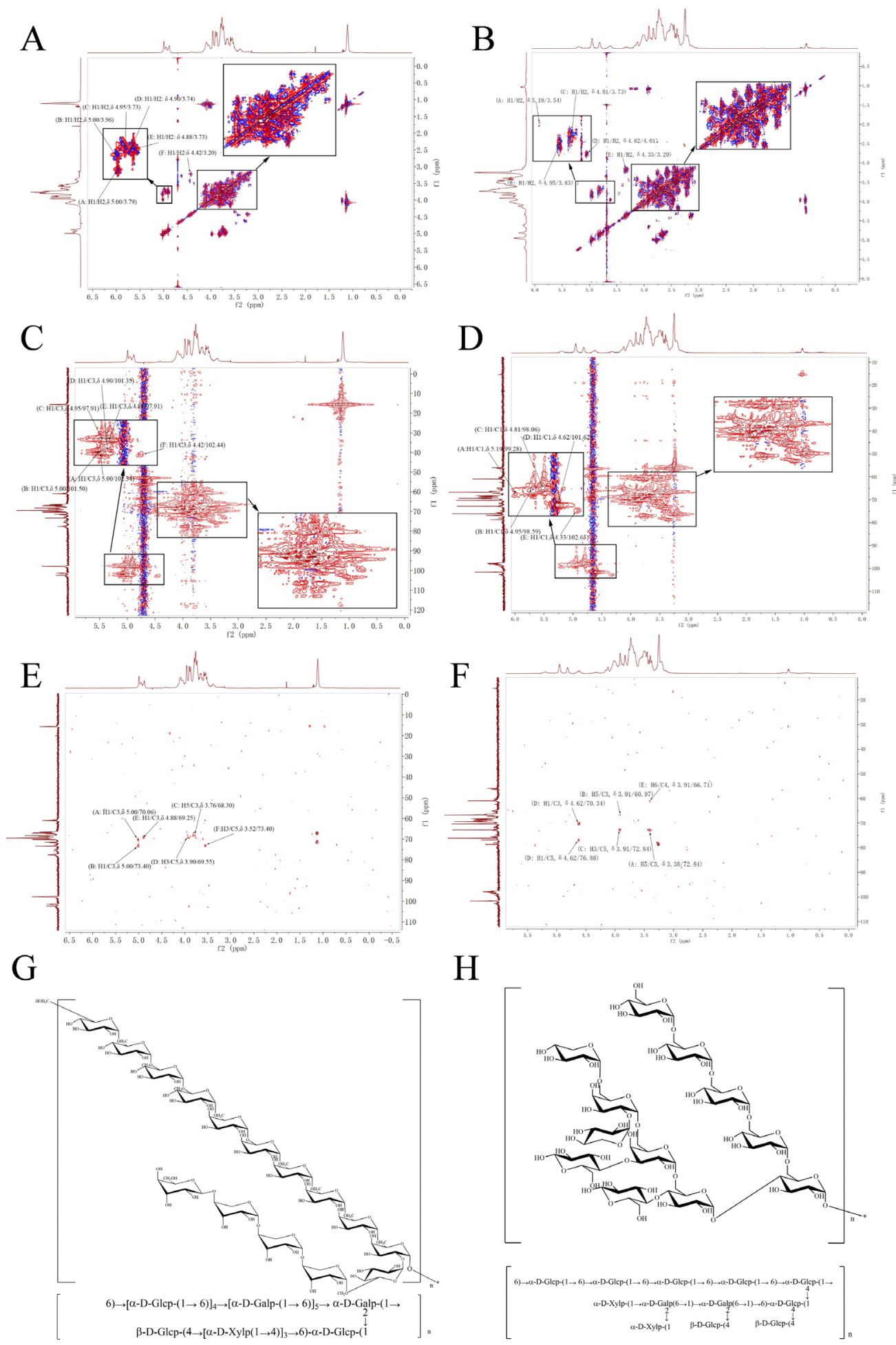

Figure 2. (A) ${ }^{1} \mathrm{H}_{-}{ }^{1} \mathrm{H}$ COSY spectrum of BA-T; (B) ${ }^{1} \mathrm{H}-{ }^{1} \mathrm{H}$ COSY spectrum of $\mathrm{PC}-1$; (C) HMQC spectrum of BA-T; (D) HMQC spectrum of PC-1; (E) HMBC spectrum of BA-T; (F) HMBC spectrum of PC-1; (G) Predicted chemical structure of BA-T; (H) Predicted chemical structure of PC-1.

5.00/3.79), B ( $\delta 5.00 / 3.96), \mathrm{C}(\delta 4.95 / 3.73), \mathrm{D}(\delta 4.90 / 3.74), \mathrm{E}$ $(\delta 4.88 / 3.73)$ and $\mathrm{F}(\delta 4.42 / 3.20)$ represented the correlation between $\mathrm{H}-1$ and $\mathrm{H}-2$ of the $(1 \rightarrow 6)$ - $\alpha$ - D-galactose residues (A), $\rightarrow 4)$ - $\beta$ - D-glucose residues (B), ( $1 \rightarrow 6)$ - $\alpha$-D-glucose residues (C), $(1 \rightarrow 2,6)$ - $\alpha$-D-glucose residues $(D),(1 \rightarrow 4)$ - $\alpha$-D-xylose residues (E) and $(1 \rightarrow 2,6)$ - $\alpha$-D-galactose residues (F), respectively. According 
to the correlation between adjacent hydrogen nuclei, the signals of $\mathrm{H} 2, \mathrm{H} 3, \mathrm{H} 4, \mathrm{H} 5$ and $\mathrm{H} 6$ in part $\mathrm{A}$ are at $\delta 3.79, \delta 3.90, \delta 3.76$, $\delta 3.50$ and $\delta 3.20$, respectively. By analogy, the hydrogen signal attribution of B, C, D, E and F is shown in Table 1.

In the ${ }^{1} \mathrm{H}^{-1} \mathrm{H}$ COSY spectrum of PC-1 (Figure $2 \mathrm{~B}$ ), the cross signal A $(\delta 5.19 / 3.54), \mathrm{B}(\delta 4.95 / 3.83), \mathrm{C}(\delta 4.81 / 3.73)$, $\mathrm{D}(\delta 4.62 / 4.01)$ and $\mathrm{E}(\delta 4.33 / 3.20)$ represented the correlation between $\mathrm{H}-1$ and $\mathrm{H}-2$ of the $\rightarrow 4)-\beta$-D-Glcp $(\mathrm{A}),(1 \rightarrow 6)-\alpha-\mathrm{D}-\mathrm{Glcp}$ (B), $(1 \rightarrow 2,6)-\alpha-D-G a l p(C), \rightarrow 1)-\alpha$-D-Xylp (D) and $(1 \rightarrow 4,6)-\alpha-D$ Glcp (E), respectively. According to the correlation between adjacent hydrogen nuclei, the signals of $\mathrm{H} 2, \mathrm{H} 3, \mathrm{H} 4, \mathrm{H} 5$ and $\mathrm{H} 6$ in part $\mathrm{A}$ are at $\delta 3.54, \delta 4.01, \delta 3.73, \delta 3.38$ and $\delta 4.12$, respectively. By analogy, the hydrogen signal attribution of $B$, $\mathrm{C}, \mathrm{D}, \mathrm{E}$ and $\mathrm{F}$ is shown in Table 2.

\subsection{HMQC analysis of polysaccharides}

The direct correlation of carbon and hydrogen signals could be obtained by HMQC spectra. In the HMQC spectrum of BA-T (Figure $2 \mathrm{C})$, the signal A $(\delta 5.00 / 102.34), \mathrm{B}(\delta 5.00 / 101.50)$, $\mathrm{C}(\delta 4.95 / 97.91), \mathrm{D}(\delta 4.90 / 101.35), \mathrm{E}(\delta 4.88 / 97.91)$ and $\mathrm{F}(\delta$ $4.42 / 102.44)$ represented the correlation between $\mathrm{H}-1$ and $\mathrm{C}-1$ of the $(1 \rightarrow 6)$ - $\alpha$ - D-galactose residues $(A), \rightarrow 4)-\beta$ - D-glucose residues (B), ( $1 \rightarrow 6)-\alpha$-D-glucose residues $(C),(1 \rightarrow 2,6)-\alpha$-D-glucose residues (D), $(1 \rightarrow 4)-\alpha$-D-xylose residues $(E)$ and $(1 \rightarrow 2,6)-\alpha-D$ galactose residues (F), respectively. According to the correlation between directly connected ${ }^{1} \mathrm{H}$ and ${ }^{13} \mathrm{C}$, the signals of $\mathrm{C} 2, \mathrm{C} 3, \mathrm{C} 4$, C5 and C6 in $\rightarrow 4$ )- $\beta$-D-Glcp (A) are $\delta 60.76, \delta 70.06, \delta 69.55, \delta$ 66.81 and $\delta 68.30$, respectively. By analogy, the hydrogen signal assignments of parts B, C, D and E are shown in Table 1.

In the HMQC spectrum of PC-1 (Figure 2D), the signal A ( $\delta$ 5.19/99.28), B ( $\delta 4.95 / 98.59), \mathrm{C}(\delta 4.81 / 98.06), \mathrm{D}(\delta 4.62 / 101.62)$ and $\mathrm{E}(\delta 4.33 / 102.65)$ represented the correlation between $\mathrm{H}-1$ and C- 1 of the $\rightarrow 4)-\beta-D-G l c p(A),(1 \rightarrow 6)-\alpha-D-G l c p(B)$, $(1 \rightarrow 2,6)-\alpha-D-G a l p(C), \rightarrow 1)-\alpha-D-X y l p(D)$ and $(1 \rightarrow 4,, 6)-\alpha-D-G l c p$ (E), respectively. According to the correlation between directly connected ${ }^{1} \mathrm{H}$ and ${ }^{13} \mathrm{C}$, the signals of $\mathrm{C} 2, \mathrm{C} 3, \mathrm{C} 4, \mathrm{C} 5$ and $\mathrm{C} 6$ in $\rightarrow 4$ )- $\beta$-D-Glcp (A) are $\delta 60.97, \delta 72.84, \delta 66.71, \delta 78.68$ and $\delta$ 65.00 respectively. By analogy, the hydrogen signal attribution of parts B, C, D and E is shown in Table 2.

\subsection{HMBC analysis of polysaccharides}

HMBC spectrum reflects the coupling relationship between ${ }^{1} \mathrm{H}$ and ${ }^{13} \mathrm{C}$, which can provide not only hydrogen signal and carbon signal, but also the connection sequence of monosaccharide residues. In the HMBC spectrum of BA-T (Figure $2 \mathrm{E}$ ), the signal $(\delta 5.00 / 70.06)$, signal $(\delta 5.00 / 73.40)$ and signal $(\delta 4.88 / 69.25)$ conformed to the correlation between $\mathrm{H}-1$ and $\mathrm{C}-3$ of the $(1 \rightarrow 6)-\alpha-\mathrm{D}$-galactose residues $(\mathrm{A}), \rightarrow 4)$ $-\beta$ - D-glucose residues $(B)$ and $(1 \rightarrow 4)$ - $\alpha$-D-xylose residues $(E)$. The chemical signal $(\delta 3.76 / 68.30)$ accorded with the correlation between $\mathrm{H}-5$ and $\mathrm{C}-3$ of $(1 \rightarrow 6)-\alpha-\mathrm{D}$-glucose residues (C). The signal $(\delta 3.90 / 69.55)$ and $(\delta 3.52 / 73.40)$ corresponded to the correlation between H-3 and C-5 of $(1 \rightarrow 2,6)-\alpha-D$-glucose residues $(D)$ and $(1 \rightarrow 2,6)$ - $\alpha$-D-galactose residues $(F)$, respectively.

In the HMBC spectrum of PC- 1 (Figure $2 \mathrm{~F}$ ), the signal ( $\delta$ $3.38 / 72.84)$ and signal $(\delta 3.91 / 60.97)$ conformed to the correlation between H-5/C-3 of $\rightarrow 4$ )- $\beta$-D-Glcp (A) and ( $1 \rightarrow 6)-\alpha-D-G l c p(B)$, respectively. Signal $(\delta 3.91 / 72.84)$ conformed to the correlation between H-3/C-5 of $(1 \rightarrow 2,6)$ - $\alpha$-D-Galp $(C)$. Signal $(\delta 4.62 / 70.34)$ and signal $(\delta 4.62 / 76.88)$ conformed to the correlation between $\mathrm{H}-1 / \mathrm{C}-3$ and H-1/C-5 of $\rightarrow 1$ )- $\alpha-\mathrm{D}-\mathrm{Xylp}(\mathrm{D})$, respectively. Signal $(\delta 3.91 / 66.71)$ conformed to the correlation between $\mathrm{H}-6 / \mathrm{C}-4$ of $(1 \rightarrow 4,6)-\alpha-D-G l c p(E)$. The above results are consistent with those of ${ }^{1} \mathrm{H}-{ }^{-1} \mathrm{H}$ cosy and HMQC.

\subsection{GC-MS analysis of polysaccharides}

Through gas chromatography and mass spectrometry (GC-MS) analysis of BA-T after methylation and silylation, the total ion current spectrum of BA-T analyzed by GC-MS, and the mass spectra of different retention times are shown in

Table 1. Chemical shifts of ${ }^{1} \mathrm{H}$ and ${ }^{13} \mathrm{C}$ NMR spectra of BA-T.

\begin{tabular}{clccccc}
\hline \multirow{2}{*}{ Glycosyl residues } & \multicolumn{5}{c}{ Chemical shifts (ppm) } \\
\cline { 2 - 6 } & \multicolumn{1}{c}{ H1/C1 } & H2/C2 & H3/C3 & H4/C4 & H5/C5 \\
\hline$(1 \rightarrow 6)-\alpha-D-G a l(A)$ & $5.00 / 102.34$ & $3.79 / 60.76$ & $3.90 / 70.06$ & $3.76 / 69.55$ & $3.50 / 66.81$ & $3.20 / 68.30$ \\
$\rightarrow 4)-\beta$ - D-Glc(B) & $5.00 / 101.50$ & $3.96 / 77.70$ & $3.74 / 73.40$ & $4.06 / 67.22$ & $3.65 / 61.08$ & $3.88 / 66.81$ \\
$(1 \rightarrow 6)-\alpha-D-G l c(C)$ & $4.95 / 97.91$ & $3.73 / 77.70$ & $3.96 / 68.30$ & $3.67 / 67.22$ & $3.76 / 70.06$ & -- \\
$(1 \rightarrow 2,6)-\alpha-D-G l c(D)$ & $4.90 / 101.35$ & $3.74 / 69.82$ & $3.90 / 67.22$ & $3.67 / 61.08$ & $3.39 / 69.55$ & $3.20 / 70.06$ \\
$(1 \rightarrow 4)-\alpha-D-X y l(E)$ & $4.88 / 97.91$ & $3.73 / 67.22$ & $3.79 / 69.25$ & $3.55 / 61.08$ & $4.09 / 68.83$ & $3.88 / 77.63$ \\
$(1 \rightarrow 2,6)-\alpha-D-G a l(F)$ & $4.42 / 102.44$ & $3.20 / 61.08$ & $3.52 / 71.76$ & $3.76 / 69.55$ & $3.65 / 73.40$ & $3.50 / 69.90$ \\
\hline
\end{tabular}

Table 2. Chemical shifts of ${ }^{1} \mathrm{H}$ and ${ }^{13} \mathrm{C}$ NMR spectra of PC-1.

\begin{tabular}{ccccccc}
\hline \multirow{2}{*}{ Glycosyl residues } & \multicolumn{5}{c}{ Chemical shifts $(\mathrm{ppm})$} \\
\cline { 2 - 7 } & $\mathrm{H} 1 / \mathrm{C} 1$ & $\mathrm{H} 2 / \mathrm{C} 2$ & $\mathrm{H} 3 / \mathrm{C} 3$ & $\mathrm{H} 4 / \mathrm{C} 4$ & $\mathrm{H} 5 / \mathrm{C} 5$ & $\mathrm{H} 6 / \mathrm{C} 6$ \\
\hline$\rightarrow 4)-\beta-\mathrm{D}-\mathrm{Glc}(\mathrm{A})$ & $5.19 / 99.28$ & $3.54 / 60.97$ & $4.01 / 72.84$ & $3.73 / 66.71$ & $3.38 / 78.68$ \\
$(1 \rightarrow 6)-\alpha-\mathrm{D}-\mathrm{Glc}(\mathrm{B})$ & $4.95 / 98.59$ & $3.83 / 68.69$ & $3.54 / 60.97$ & $3.66 / 68.46$ & $3.40 / 66.71$ & $3.50 / 69.41$ \\
$(1 \rightarrow 2,6)-\alpha-D-G a l(\mathrm{C})$ & $4.81 / 98.06$ & $3.73 / 76.88$ & $3.91 / 70.34$ & $3.54 / 66.71$ & $3.45 / 72.84$ & $3.38 / 68.69$ \\
$\rightarrow 1)-\alpha-\mathrm{D}-\mathrm{Xyl}(\mathrm{D})$ & $4.62 / 101.62$ & $4.01 / 68.69$ & $3.58 / 70.34$ & $3.66 / 69.41$ & $3.42 / 76.88$ & -- \\
$(1 \rightarrow 4,, 6)-\alpha-\mathrm{D}-\mathrm{Glc}(\mathrm{E})$ & $4.33 / 102.65$ & $3.20 / 76.88$ & $3.42 / 68.46$ & $3.54 / 66.71$ & $3.77 / 60.97$ & $3.91 / 69.41$ \\
\hline
\end{tabular}


Table 3. The results showed that the $\beta$-D-glucose residue was 2,3,6-tri-O-methyl-4-O-trimethylsilyl-Glcp, indicating that there was a 4 -linked $\beta$-D-glucose residue in BA-T. The $\alpha$-D-glucose residues are 2,3,4-tri-O-methyl-1,6-bis-O-trimethylsilyl-Glcp, indicating that there are 1,6 -linked $\alpha$ - $\mathrm{D}$-glucose residues in BA-T. The xylose residues are 2-O-methyl-1,3,4-tris-O- (trimethylsilyl) - Xylp and 3-O-methyl-1,2,4-tris-O- (trimethylsilyl) - Xylp and there are two forms of $\alpha$-D-galactose residues: 2,4-di-o-methyl1,3,6-tris-o-trimethylsilyl-Galp and 3,4-di-o-methyl-1,2,6-triso-trimethylsilyl-Galp. Considering that the steric hindrance of $\mathrm{C} 2$ and $\mathrm{C} 3$ on the monosaccharide ring is large, it is easy to cause incomplete methylation, so it is speculated that the linkage mode of Xylose residues in BA-T is 1,4-linkage, and the galactose is connected by 1,6 -linkage.

The results of GC-MS analysis of PC- 1 showed that the $\beta$-Dglucose residue was 2,3,6-tri-O-methyl-4-O-trimethylsilyl-Glcp, indicating that there was a 4 -linked $\beta$ - D-glucose residue in PC-1. There are 2,3,4-tri-O-methyl-1,6-bis-O-trimethylsilyl-Glcp and 2,3-di-O-methyl-1,4,6-bis-O-trimethylsilyl-Glcp in the $\alpha$-D-glucose residues, indicating that there are 1,6-linked and 1,4,6-linked $\alpha$ - D-glucose residues in PC-1. The xylose residue is 2,3,4-tri-omethyl-1-O- (trimethylsilyl)-Xylp, which indicates that there is a xylose residue linked at $\mathrm{C} 1$ in $\mathrm{PC}-1$. The $\alpha$ - D-galactose residue is 3,4-di-O-methyl-1,2,6-tris-O- (trimethylsilyl) -Galp, which indicates that there are 1,2,6-linked galactose residues in PC-1 (Table 4).

The results of structure identification by GC-MS, HPGPC, HPLC, FT-IR and NMR showed that BA-T was composed of xylose residues, glucose residues and galactose residues, and the ratio is 3:6:6. The BA-T takes 1,6-glucose and 1,6-galactose as skeletons, extends a branched chain from galactose $2-\mathrm{O}$ to connect 1,4-xylose, and connects $\beta$-4-glucose terminal monosaccharide to xylose. PC-1 was composed of xylose, glucose and galactose in the ratio of 2:8:2. In accordance with FT-IR, monosaccharide composition and methylation results of PC-1, it was inferred that PC-1 takes 1,6-glucose as skeletons, extends a branched chain from galactose $4-\mathrm{O}$ to connect $(1 \rightarrow 4,6)-\alpha-\mathrm{D}-\mathrm{Glcp}$ and
$(1 \rightarrow 2,6)$ - $\alpha$-D-galactose, and $\rightarrow 4)-\beta$-D-Glcp and $\rightarrow 1)$ - $\alpha$-D-Xylp as terminal group. The structure of BA-T and PC-1 were shown in Figure 2G, H, repectively.

\subsection{Effect of BA-T and PC-1 on T cell proliferation}

T cells were differentiated from bone marrow stem cells, which could participate in the cellular immunity of the body (Park et al., 2005). The analysis of results showed that polysaccharide group of BA-T and PC-1 (final concentration 2.5, 5, $10 \mu \mathrm{g} / \mathrm{mL}$, respectively) could significantly promote the proliferation of $\mathrm{T}$ cells compared with the blank control group (Figure 3A, B). When the concentration of BA-T was $5 \mu \mathrm{g} / \mathrm{mL}$ and PC- 1 was $15 \mu \mathrm{g} / \mathrm{mL}$, the proliferation efficiency of $\mathrm{T}$ cells reached the maximum and increased by $101.98 \%$ and $57.62 \%$, respectively, and was higher than that of the positive control group (LPS was $5 \mu \mathrm{g} / \mathrm{mL}$ ), whcih were $29.60 \%$ and $26.70 \%$, respectively. Cell morphology observation demonstrated that compared with cells in blank control group, cells stimulated by BA-T and PC-1 formed large clusters and increased in number.

\subsection{Effect of BA-T and PC-1 on proliferation of B cells}

$B$ cells were derived from the pluripotent stem cells of bone marrow, which could proliferate and differentiate into a large number of plasma cells when stimulated by antigens. Plasma cells could synthesize and secrete antibodies in the blood circulation, which plays an important role in the development and regulation of the immune system (Whillock et al., 2021). The results indicated that when the final mass concentration of polysaccharide was $2.5-20 \mu \mathrm{g} / \mathrm{ml}$, the proliferation effect of $B$ cells was enhanced. When the final concentration of BA-T and PC-1 was $10 \mu \mathrm{g} / \mathrm{ml}$, the effect of promoting B cell proliferation was the best, and the proliferation rate reached $68.88 \%$ and $34.58 \%$, respectively, and was higher than that of the positive control group (LPS was $5 \mu \mathrm{g} / \mathrm{mL}$ ), whcih were $34.97 \%$ and $22.47 \%$, respectively (Figure 3C, D). B cells grew well, mostly round, and grew in clusters. When polysaccharide

Table 3. Methylation analysis of monosaccharides in BA-T.

\begin{tabular}{ccc}
\hline Methylated sugar & Linkage & $\mathrm{m} / \mathrm{z}$ \\
\hline 4-O-trimethylsilyl- Glcp & $4-$ & 59738588101116133146159174187207219229261 \\
1,6-bis-O-trimethylsilyl-Glcp & $1,6-$ & 597388101117133145159174205229245265287319351 \\
1,2,4-tris-O-(trimethylsilyl)-Xylp & $1,2,4-$ & 597389101133146159173191217233265290305333 \\
1,3,4-tris-O-(trimethylsilyl)-Xylp & $1,3,4-$ & 59738589101116133146159169189204217231247259275291 \\
1,3,6-tris-O- trimethylsilyl-Galp & $1,3,6-$ & 305333348 \\
1,2,6-tris-O-trimethylsilyl-Galp & $1,2,6-$ & 597389103117133146159173189205232259277317345377 \\
\hline
\end{tabular}

Table 4. Methylation analysis of monosaccharides in PC-1.

\begin{tabular}{ccc}
\hline Methylated sugar & Linkage & $\mathrm{m} / \mathrm{z}$ \\
\hline 1,6-bis-O-trimethylsilyl-Glcp & $1,6-$ & 597388101117133145159174185205217233229245265287319 \\
1,4,6-bis-O-trimethylsilyl-Glcp & $1,4,6-$ & 597388103117133147159191205232229259287319345377 \\
4-O-trimethylsilyl- Glcp & $4-$ & 597388101116133146159174187207229261293 \\
1-O-(trimethylsilyl)-Xylp & $1-$ & 58738588101115121133149159174185217249 \\
1,2,6-tris-O-trimethylsilyl-Galp & $1,2,6-$ & 597389103117133146159173189205232259277317345377 \\
\hline
\end{tabular}



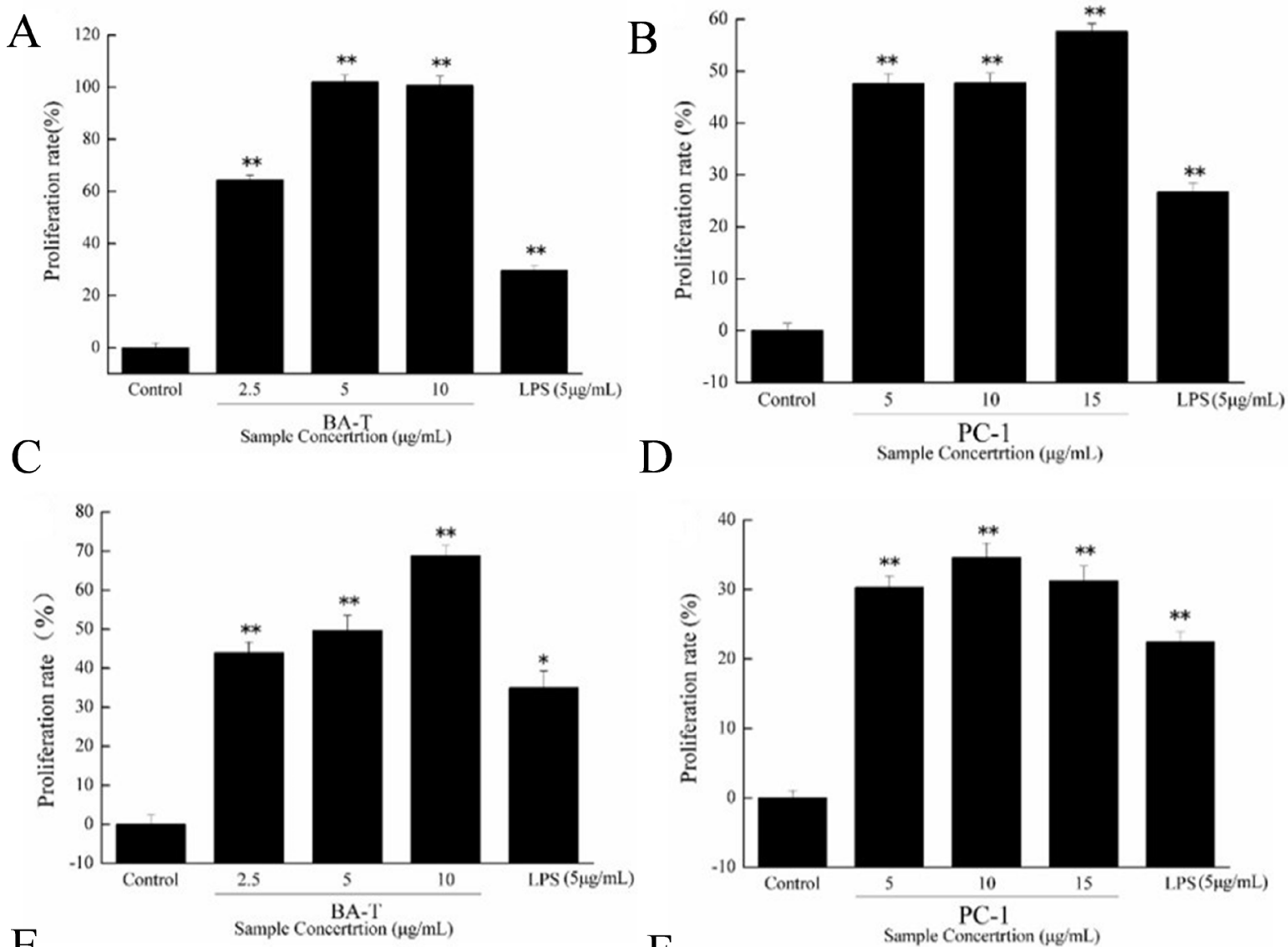

E

$\mathrm{F}$
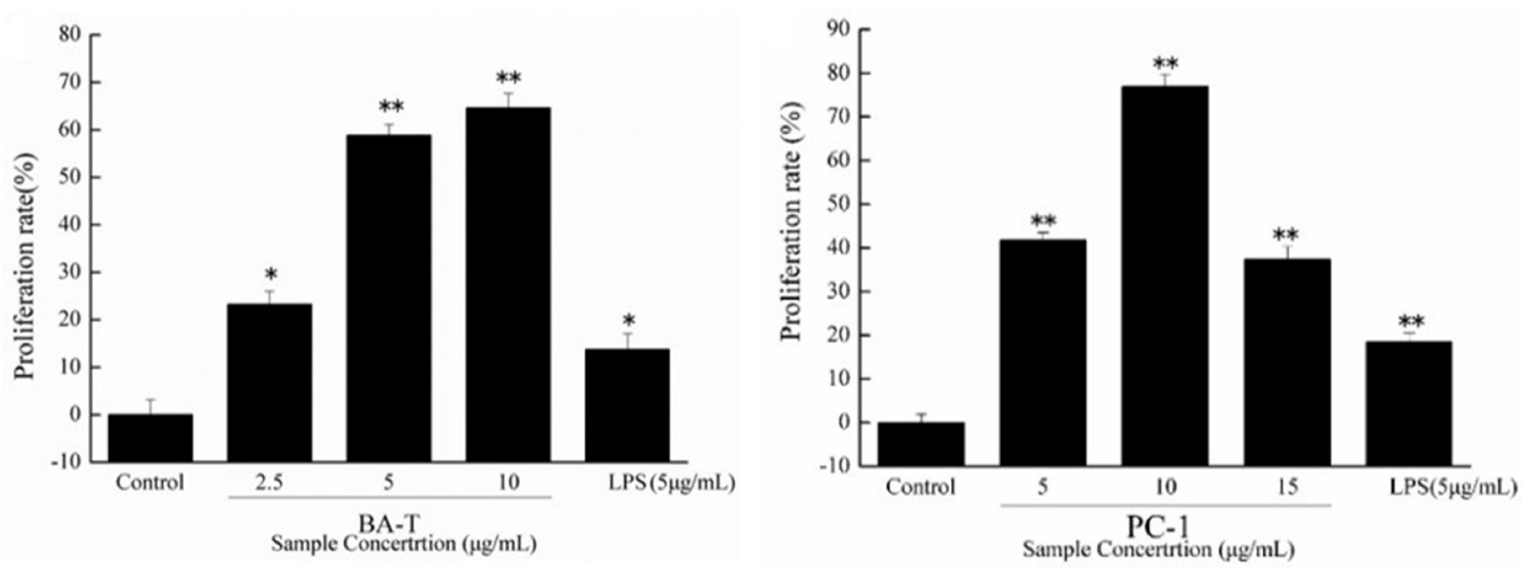

Figure 3. (A) Effect on the proliferation of T cells by BA-T; (B) Effect on the proliferation of T cells by PC-1; (C) Effect on the proliferation of B cells by BA-T. (D) Effect on the proliferation of B cells by PC-1; (E) Effect on the proliferation of RAW264.7 cells by BA-T; (F) Effect on the proliferation of RAW264.7 cells by PC-1. Note: Compared with the control group, the difference was significant $(\mathrm{P}<0.05)$ expressed by ${ }^{\star}$ and very significant $(\mathrm{P}<0.01)$ expressed by ${ }^{* *}$.

was increased, the number of cells and the volume of cell colony also increased.

\subsection{Effect of BA-T on proliferation of RAW264.7 cells}

RAW264.7 cells has a variety of immune functions and strong ability of adhesion and phagocytosis of antigens. They could not only participate in innate immunity of the body, but also play an important role in immune regulation by participating in acquired immunity (Iwamoto et al., 2005). As shown in Figure $3 \mathrm{E}$, F, when the final mass concentration of polysaccharide was $5-15 \mu \mathrm{g} / \mathrm{ml}$, the proliferation effect of RAW264.7 cells increases with the increase of different concentrations of polysaccharide. When the final concentration of BA-T and 
PC-1 was $10 \mu \mathrm{g} / \mathrm{ml}$, the proliferation rate of RAW264.7 cells was $76.91 \%$ and $64.61 \%$, respectively, and was higher than that of the positive control group (LPS was $5 \mu \mathrm{g} / \mathrm{mL}$ ), whcih were $18.54 \%$ and $13.72 \%$, respectively. RAW 264.7 macrophage was in the state of high refraction circle and part of cells extend pseudopodia, and adheres to the wall under the stimulation of polysaccharide BA-T and PC-1.

\subsection{Quantitative analysis of gene expression}

In the screening of the two polysaccharides on the proliferation of immune cells, BA-T has a strong immune proliferation activity on $\mathrm{T}$ cells. Transcriptome analysis was done to explore the molecular mechanism of BA-T on $\mathrm{T}$ cells proliferation. After RNA-sequencing of T cells of control, BA-T and LPS groups, raw data (raw reads) were obtained, respectively. After removing the spliced reads and low-quality reads, $8.21 \mathrm{G}$ (Control), $8.30 \mathrm{G}$ (BA-T) and 8.26 G (LPS) analysis data (clean Reads) were obtained, respectively. In control group, Q20 (\%) was 97.87\%, Q30 (\%) was 93.93\%, GC content was 49.47\%; in BA-T group, Q20 (\%) was 97.87\%, Q30 (\%) was 93.94\%, GC content was 49.47\%; in LPS group, Q20 (\%) was 97.87\%, Q30 (\%) was 93.86\%, GC content was $49.69 \%$, and the base error rate was all $0.03 \%$. According to the reference sequence alignment analysis, 53385212 readings (97.59\%) were successfully compared in the control group, of which 52061527 (95.18\%) were the only readings compared to the reference genome, and 1323685 (2.41\%) were compared to multiple locations in the reference genome. In BA-T group, 54012626 readings $(97.66 \%)$ were compared successfully, of which 57360186 (95.21\%) were the only readings compared to the reference genome, and 1359758 (2.45\%) were compared to multiple locations of the reference genome. In LPS group, 53754649 readings $(97.60 \%$ ) were compared successfully, of which $54632832(95.16 \%)$ were the only readings compared to the reference genome, and 1345592 (2.44\%) were compared to multiple locations of the reference genome. The above results show that the sequencing results were reliable and could be used for the next analysis and research.

In this experiment, FPKM method was used to estimate the gene expression level (Hart et al., 2013). It is generally believed that genes with FPKM over 60 are expressed at a high level, while genes with FPKM over 0-0.1 are expressed at a low level or not at all. The results of gene expression level analysis showed that although the gene expression levels of control group, BA-T group and LPS positive control group were similar, there were still some differences. In the control group, 13243 genes were expressed (FPKM > 1), accounting for $22.55 \%$ of the total genes. Among them, 602 genes were highly expressed (FPKM $>60)$, accounting for $1.03 \%$ of the total genes. In BA-T group, 12867 genes were expressed (FPKM $>1$ ), accounting for $21.91 \%$ of the total genes. Among them, 655 genes were highly expressed $(\mathrm{FPKM}>60)$, accounting for $1.12 \%$ of the total genes. 13026 genes (FPKM $>1$ ), accounting for $22.12 \%$ of the total number of genes, were expressed in LPS and LPS positive control group (LPS). Among them, 636 genes were highly expressed (FPKM $>60$ ), accounting for $1.08 \%$ of the total number of genes.

Further analysis showed that there were 8 over expressed genes in the control group (MT-CO1, MT-ND4, MT-CO2, MT-CO3, MT-ATP6, MT-CYB, MT-ND2, MT-ND4L), 7 over expressed genes in the BA-T group (MT-CO1, MT-ND4, MT-CO2, MTCO3, MT-ATP6, MT-ND2, MT-ND4L), and 7 over expressed genes in the LPS positive control group (LPS)(MT-CO1, MTND4, MT-CO2, MT-CO3, MT-ATP6, MT-ND2, MT-ND4L).

MT-CO1, MT-CO2 and MT-CO3 are the genes encoding subunit I, subunit II and subunit III of cytochrome c oxidase (Holvoet et al., 2016; Tabebi et al., 2015), MT-ND4, MT-ND2 and MT-ND4L are the genes encoding NADH: ubiquinone oxidoreductase core subunit 4, subunit 2 and 4L (Mathews et al., 2005), MT-ATP6 is the gene encoding ATP synthase membrane subunit 6 , and mitochondrial ATP synthase is the key enzyme of oxidative phosphorylation (Pitceathly et al., 2012). MT-CO1, MT-ND4, MT-CO2, MT-CO3, MT-ATP6, MT-ND2 and MT-ND4L genes were highly expressed in control, BA-T and LPS groups, indicating that BA-T and LPS did not change the energy metabolism site of $\mathrm{T}$ cell proliferation (Jurkat cell line), and mitochondria were still the main energy source of $\mathrm{T}$ cell proliferation.

\subsection{Differential gene analysis}

After quantitative analysis of gene expression, statistical analysis of gene expression data was carried out to screen the genes with significant expression differences in different samples under the same conditions. Based on the three biological repeats in this experiment, the significance of gene differential expression was analyzed by using DESeq2 software, and $\mid \log 2$ (foldchange) $\mid>$ 0 and $\operatorname{Padj}<0.05$ was used as the screening criteria. The results are shown in Figure 4A, B. Compared with the blank group, there were 600 genes up-regulated and 822 genes down regulated in BA-T group (Figure 4A), among which 10 genes up-regulated were Smn1, Gapdh, Psmb7, Pkm, Snrpb, Rps5, Cdc123, Mrps34, Ac139272.1 and ps13. Compared with the blank control group, there were 702 genes in the LPS positive control group, of which 544 genes were up-regulated and 71 genes were down regulated (Figure 4B). Among them, 10 genes were up-regulated, including Rabggtb, Nop53, Stag3l, Hnrnpa1, Pkm, Rpl13A, H3f3b, Runx1, Atf4 and Eef1a1.

Gapdh is the gene encoding glyceraldehyde 3-phosphate dehydrogenase (GAPDH), GAPDH is the key enzyme in the process of glycolysis (Hara et al., 2005); $\mathrm{Pkm}$ is the gene encoding pyruvate kinase (PKM), PKM promotes the production of pyruvate in the process of glycolysis (Shema et al., 2007), and Gapdh and $P \mathrm{~km}$ are up-regulated in BA-T group, which indicates that the intracellular glucose metabolism process is more vigorous under the stimulation of BA-T. Psmb7 is a gene encoding proteasome $\beta 7$ subunit (Munkácsy et al., 2010). Psmb7 is up-regulated in BA-T group, suggesting that BA-T contributes to increase intracellular protein metabolism. $C d c 123$ is a gene of cell cycle division protein 123 (CDC123) (Imamura et al., 2011). CDC123 is a cell cycle regulator required for eukaryotic initiation factor 2 (eIF2) assembly. Cdc123 is up-regulated in BA-T group, suggesting that BA-T plays an important role in regulating protein synthesis, cell growth and proliferation.

\subsection{Go enrichment analysis of differential genes}

Go (Gene Ontology) is a comprehensive database describing gene function, which is divided into three parts: biological 

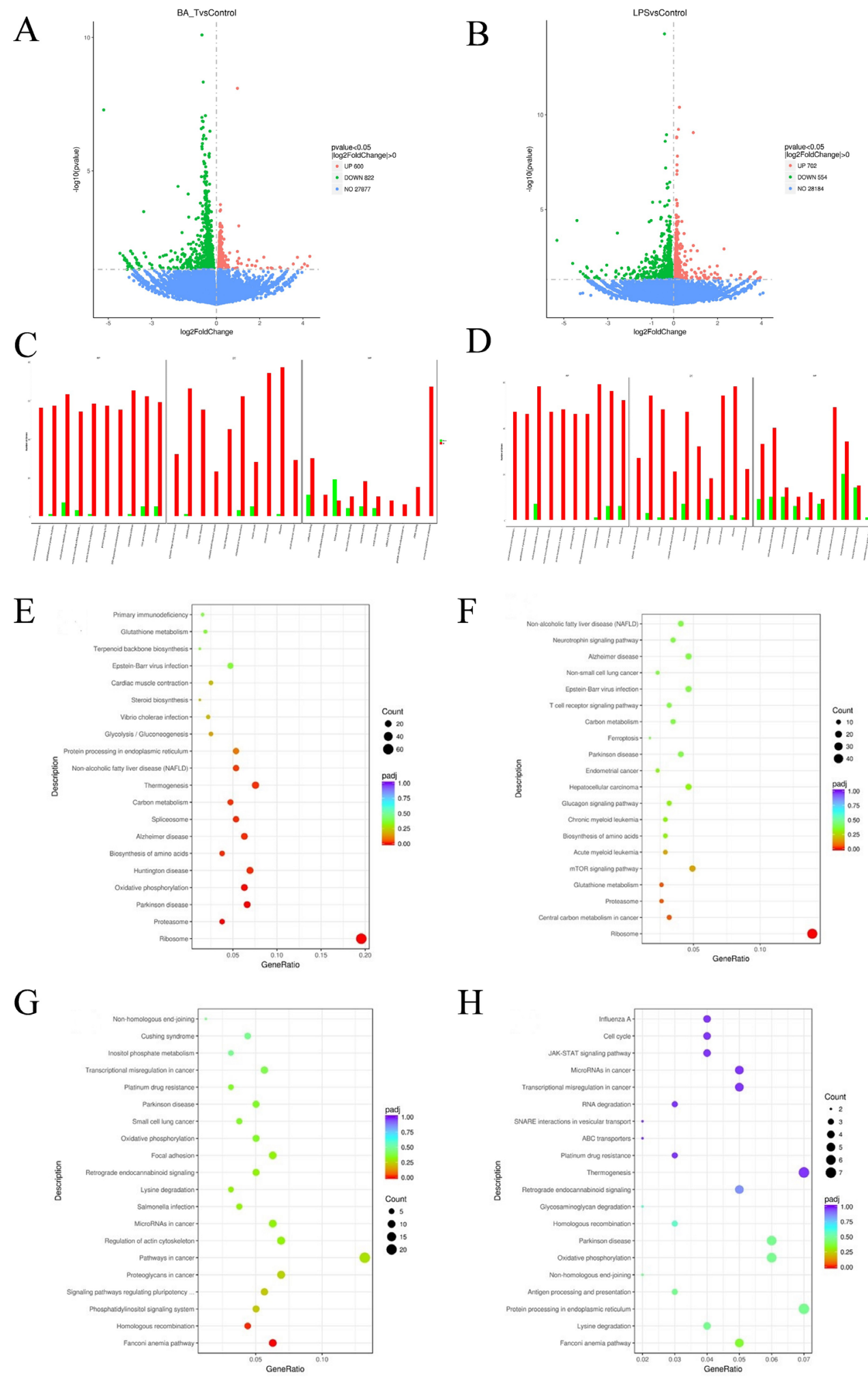

Figure 4. (A) Volcanic map analysis of differential gene expression of BA-T group compared with control group; (B) Volcanic map analysis of differential gene expression of LPS group compared with control group; (C) Classification and analysis of gene function of BA-T group compared with Control group; (D) Classification and analysis of gene function of LPS group compared with Control group; (E) Top 20 KEGG pathways enriched for up-regluated differentially expressed genes between BA-T and Control group; (F) Top 20 KEGG pathways enriched for downregluated differentially expressed genes between BA-T and Control group; $(\mathrm{G})$ Top 20 KEGG pathways enriched for up-regluated differentially expressed genes between LPS and Control group; (H) Top 20 KEGG pathways enriched for down-regluated differentially expressed genes between LPS and Control group. 
process, cellular component and molecular function. A total of 9116 differential genes (padj < 0.05 ) between BA-T and blank group were successfully annotated, among which 7191 genes were up-regulated and 1925 genes were down regulated (Figure 4C). Among them, ribonucleoprotein complex biogenesis is the most abundant gene in biological process, ribosome is the most abundant gene in cell component, and structural construct of ribosome is the most abundant gene in molecular function. A total of 5751 differential genes (padj < 0.05 ) were successfully annotated between LPS group and blank group, of which 4729 genes were up-regulated and 1022 genes were down regulated (Figure 4D). Among them, translation initiation is the most abundant in biological processes, ribosome is the most abundant in cell components, and structural construct of ribosome is the most abundant in molecular functions. The results showed that there were differences between BA-T group, LPS group and blank group in gene types of biological process, cell composition and molecular function. However, it should be noted that the effect of BA-T on T cells may be similar to that of LPS.

\subsection{KEGG enrichment analysis of differential genes}

In order to investigate the effect of BA-T and LPS on T cell proliferation, the KEGG (Kyoto Encyclopedia of genes and genomes) pathway was analyzed by cluster profiler software. The differential genes among BA-T group, LPS group and blank group were annotated in KEGG database. A total of 476 (8.36\%) differential genes between BA-T group and blank group were successfully annotated into 283 pathways, and 445 (7.95\%) differential genes between LPS group and blank group were successfully annotated into 281 pathways. By analyzing the top 20 pathways of differentially expressed genes (padj < 0.05 ) between BA-T group and blank group, it was found that there were 11 up-regulated genes in BA-T, mainly including ribosome, proteasome and oxidative phosphorylation (Figure 4E). The down regulated genes in BA-T significantly enriched include Fanconi anemia pathway and homologous recombination (Figure 4F). By analyzing the top 20 pathways of differentially expressed genes (padj < 0.05) between LPS group and blank group, it was found that there were 4 up-regulated genes in LPS, including ribosome, central carbon metabolism in cancer, proteasome, and glutathione metabolism pathway (Figure $4 \mathrm{G}$ ), while there were no significantly enriched down regulated genes in LPS (Figure $4 \mathrm{H}$ ).

Further analysis of the signal pathway between BA-T group and blank group showed that 62 differentially expressed genes (13.03\%) were up-regulated in ribosomal pathway, 20 (4.20\%) were up-regulated and $8(1.68 \%)$ were down regulated in oxidative phosphorylation pathway. The expression of Gapdh (glyceraldehyde 3-phosphate dehydrogenase), Bpgm (phosphoglycerate mutase), Pgk (phosphoglycerate kinase), Pgam (phosphoglycerate kinase), Eno (enolase), $P \mathrm{~km}$ (pyruvate kinase), $P d h$ (pyruvate dehydrogenase) and $L d h$ (lactate dehydrogenase) in glycolysis pathway were up-regulated, while the expression of Aldh (aldehyde dehydrogenase) was down regulated. The expression of $P d h$ (pyruvate dehydrogenase), Aco (Aconitum hydrolase), Idh (isocitrate dehydrogenase) and $O g d h$ (oxoglutarate dehydrogenase) in the tricarboxylic acid cycle were up-regulated. It is suggested that the protein synthesis and metabolism of $\mathrm{T}$ cells are more vigorous under the stimulation of BA-T, and oxidative phosphorylation is the main energy source in the process of $\mathrm{T}$ cell proliferation.

\section{Conclusion}

In this study, hot water extraction, ethanol precipitation, DEAE-52 cellulose and column chromatography were used to extract and purify the crude polysaccharides of Boletus aereus and Pleurotus cornucopiae. Two new polysaccharides were extracted from the fruiting bodies of Boletus aereus and Pleurotus cornucopiae, respectively. In this study, two new polysaccharides were extracted from the fruiting bodies of Boletus aereus and Pleurotus cornucopiae, respectively, by hot water extraction, ethanol precipitation and DEAE column chromatography. The results showed that the molecular weight of Boletus aereus polysaccharide (BA-T) was $14552 \mathrm{Da}$, and that of Pleurotus cornucopiae (PC-1) was $26606 \mathrm{Da}$. The results of structure identification by GC-MS, HPGPC, HPLC, FT-IR and NMR showed that BA-T was composed of xylose residues, glucose residues and galactose residues, and the ratio is 3:6:6. The BA-T takes 1,6-glucose and 1,6-galactose as skeletons, extends a branched chain from galactose $2-\mathrm{O}$ to connect 1,4-xylose, and connects $\beta$-4-glucose terminal monosaccharide to xylose. PC-1 was also composed of of xylose, glucose and galactose in the ratio of 2:8:2. In accordance with FT-IR, monosaccharide composition and methylation results of PC-1, it was inferred that PC-1 takes 1,6-glucose as skeletons, extends a branched chain from galactose 4 -O to connect $(1 \rightarrow 4,6)-\alpha-\mathrm{D}-\mathrm{Glcp}$ and $(1 \rightarrow 2,6)$ - $\alpha$-D-galactose, and $\rightarrow 4)-\beta$-D-Glcp and $\rightarrow 1)$ - $\alpha$-D-Xylp as terminal group. The results of immunoactivity showed that BA-T and PC- 1 have the proliferation activity of B cells, T cells and RAW264.7 cells in vitro, and the effect of BA-T on the proliferation of $\mathrm{T}$ cells was the greatest. In addition, $\mathrm{BA}-\mathrm{T}$ could significantly promote the secretion of $\operatorname{IgA}$, IgE, IgG and IgM in B cells and enhance the phagocytic ability of RAW264.7 cells. The results of RNA-sequencing showed that the protein synthesis and metabolism of $\mathrm{T}$ cells are more vigorous under the stimulation of BA-T, and oxidative phosphorylation is the main energy source in the process of $\mathrm{T}$ cell proliferation. In conclusion, BA-T and PC-1 were both natural polysaccharides with novel structure, which had immune and proliferationactivity for specific immune cells. To explore the structure of Boletus aereus polysaccharide (BA-T) and Pleurotus cornucopiae polysaccharide (PC-1) and the structure-activity relationship between them can provide a better theoretical basis for the research and development of medicinal value of BA-T and PC- 1 .

\section{Conflict of interest}

The author declare that they have no conflict of interest.

\section{Availability of data and material}

The datasets used and/or analyzed during the current study are available from the corresponding author on reasonable request.

\section{Funding}

This project was supported by the Open Project Program of Irradiation Preservation Technology Key Laboratory of Sichuan Province, Sichuan Institute of Atomic Energy (FZBC2020009), the 
Open Research Fund Program of Departmental and Municipal Co-construction of Crops Genetic Improvement Of Hill Land Key Laboratory of Sichuan Province (2021CGIHL02), Science and Technology Support Project of Nanchong science and Technology Bureau of Sichuan Province (20YFZJ0053 and 20YFZJ0054).

\section{Authors' contributions}

Yiling Hou conceived and designed the experiments of the present study. Xiang Ding, Xian Tang and Yiling Hou performed the experiments and acquired data. Xiang Ding and Yiling Hou drafted the manuscript and revised it critically. All authors read and approved the final manuscript.

\section{References}

Aydogan-Coskun, B., Coklar, H., \& Akbulut, M. (2020). Effect of heat treatment for liquefaction and pasteurization on antioxidant activity and phenolic compounds of Astragalus and sunflower-cornflower honeys. Food Science and Technology, 40(3), 629-634. http://dx.doi. org/10.1590/fst.15519.

Byeon, S. E., Lee, J., Lee, E., Lee, S. Y., Hong, E. K., Kim, Y. E., \& Cho, J. Y. (2009). Functional activation of macrophages, monocytes and splenic lymphocytes by polysaccharide fraction from Tricholoma matsutake. Archives of Pharmacal Research, 32(11), 1565-1572. http:// dx.doi.org/10.1007/s12272-009-2108-y. PMid:20091269.

Chaturvedi, V.K., Agarwal, S., Gupta, K.K., Ramteke, P.W., \& Singh, M.P. (2018). Medicinal mushroom: boon for therapeutic applications. 3 Biotech, 8, 334-353.

Chihara, G., Hamuro, J., Maeda, Y. Y., Shiio, T., Suga, T., Takasuka, N., \& Sasaki, T (1987). Antitumor and metastasis-inhibitory activities of lentinan as an immunomodulator: an overview. Cancer Detection and Prevention. Supplement, 1, 423-443. PMid:3319150.

Guo, M. Z., Meng, M., Duan, S. Q., Feng, C. C., \& Wang, C. L. (2019). Structure characterization, physicochemical property and immunomodulatory activity on RAW264.7 cells of a novel triplehelix polysaccharide from Craterellus cornucopioides. International Journal of Biological Macromolecules, 126, 796-804. http://dx.doi. org/10.1016/j.ijbiomac.2018.12.246. PMid:30594621.

Hagiwara, S., Takahashi, M., Shen, Y., Kaihou, S., Tomiyama, T., Yazawa, M., Tamai, Y., Sin, Y., Kazusaka, A., \& Terazawa, M. (2005). A Phytochemical in the edible Tamogi-take mushroom (Pleurotus cornucopiae), D -mannitol, inhibits ACE activity and lowers the blood pressure of spontaneously hypertensive rats. Bioscience, Biotechnology, and Biochemistry, 69(8), 1603-1605. http://dx.doi. org/10.1271/bbb.69.1603. PMid:16116292.

Hara, M. R., Agrawal, N., Kim, S. F., Cascio, M. B., Fujimuro, M., Ozeki, Y., Takahashi, M., Cheah, J. H., Tankou, S. K., Hester, L. D., Ferris, C. D., Hayward, S. D., Snyder, S. H., \& Sawa, A. (2005). S-nitrosylated gapdh initiates apoptotic cell death by nuclear translocation following siah1 binding. Nature Cell Biology, 7(7), 665-674. http://dx.doi. org/10.1038/ncb1268. PMid:15951807.

Hart, T., Komori, H. K., Lamere, S., Podshivalova, K., \& Salomon, D. R. (2013). Finding the active genes in deep rna-seq gene expression studies. BMC Genomics, 14(1), 778. http://dx.doi.org/10.1186/14712164-14-778. PMid:24215113.

He, S., Ma, X., Meng, Q., Lu, J., Qin, X., Fang, S., \& Ma, C. (2020). Effects and mechanisms of water-soluble Semen cassiae polysaccharide on retinitis pigmentosa in rats. Food Science and Technology, 40(1), 84-88. http://dx.doi.org/10.1590/fst.32718.
Holvoet, P., Vanhaverbeke, M., Bloch, K., Baatsen, P., Sinnaeve, P., \& Janssens, S. (2016). Low mt-col in monocytes and microvesicles is associated with outcome in patients with coronary artery disease. Journal of the American Heart Association, 5(12), e004207. http:// dx.doi.org/10.1161/JAHA.116.004207. PMid:27919931.

Hu, J., Gao, J., Zhao, Z., \& Yang, X. (2021). Response surface optimization of polysaccharide extraction from Galla Chinensis and determination of its antioxidant activity in vitro. Food Science and Technology, 41(1), 188-194. http://dx.doi.org/10.1590/fst.38619.

Imamura, M., Iwata, M., Maegawa, H., Watada, H., Hirose, H., Tanaka, Y., Tobe, K., Kaku, K., Kashiwagi, A., Kawamori, R., Nakamura, Y., \& Maeda, S. (2011). Genetic variants at cdc123/camk1d and spry2 are associated with susceptibility to type 2 diabetes in the japanese population. Diabetologia, 54(12), 3071-3077. http://dx.doi. org/10.1007/s00125-011-2293-3. PMid:21909839.

Ismail, G. A., Gheda, S. F., Aboshady, A. M., \& Abdelkarim, O. H. (2020). In vitro potential activity of some seaweeds as antioxidants and inhibitors of diabetic enzymes. Food Science and Technology, 40(3), 681-691. http://dx.doi.org/10.1590/fst.15619.

Iwamoto, M., Kurachi, M., Nakashima, T., Kim, D., Yamaguchi, K., Oda, T., Iwamoto, Y., \& Muramatsu, T. (2005). Structure-activity relationship of alginate oligosaccharides in the induction of cytokine production from Raw264.7 cells. FEBS Letters, 579(20), 4423-4429. http://dx.doi.org/10.1016/j.febslet.2005.07.007. PMid:16055120.

Karaoğlan, S. Y., \& Cabaroğlu, T. (2020). A comparison of the volatile and phenolic compositions of Muscat of Bornova wines from two different terroirs in the Aegean region of Turkey. Food Science and Technology, 40(4), 844-853. http://dx.doi.org/10.1590/fst.21819.

Kim, H., Cho, S. M., Kim, W. J., Hong, K., Suh, H. J., \& Yu, K. W. (2021). Red ginseng polysaccharide alleviates cytotoxicity and promotes anti-inflammatory activity of ginsenosides. Food Science and Technology [Ahead of print].

Lee, S. R., Lee, D., Lee, H. J., Noh, H. J., Jung, K., Kang, K. S., \& Kim, K. H. (2017). Renoprotective chemical constituents from an edible mushroom, Pleurotus cornucopiae, in cisplatin-induced nephrotoxicity. Bioorganic Chemistry, 71, 67-73. http://dx.doi.org/10.1016/j. bioorg.2017.01.012. PMid:28129885.

Li, H., Zhang, H., Zhang, Z., \& Cui, L. (2020). Optimization of ultrasound-assisted enzymatic extraction and in vitro antioxidant activities of polysaccharides extracted from the leaves of Perilla frutescens. Food Science and Technology, 40(1), 36-45. http://dx.doi. org/10.1590/fst.29518.

Li, L., Xue, Y., Zhang, H., Liu, Y., Yi, F., \& Dong, Y. (2021). A new polysaccharide isolated from Dendrobium offcinale, stimulates aquaporin-3 expression in human keratinocytes. Food Science and Technology, 41(1), 90-95. http://dx.doi.org/10.1590/fst.31119.

Liu, Y., \& Li, S. (2021). Extraction optimization and antioxidant activity of Phyllanthus urinaria polysaccharides. Food Science and Technology, 41(Suppl. 1), 91-97. http://dx.doi.org/10.1590/fst.11320.

Mathews, C. E., Leiter, E. H., Spirina, O., Bykhovskaya, Y., Gusdon, A. M., Ringquist, S., \& Fischel-Ghodsian, N. (2005). Mt-nd2 allele of the alr/lt mouse confers resistance against both chemically induced and autoimmune diabetes. Diabetologia, 48(2), 261-267. http:// dx.doi.org/10.1007/s00125-004-1644-8. PMid:15692809.

Meng, X., Liang, H., \& Luo, L. (2016). Antitumor polysaccharides from mushrooms: a review on the structural characteristics, antitumor mechanisms and immunomodulating activities. Carbohydrate Research, 424, 30-41. http://dx.doi.org/10.1016/j.carres.2016.02.008. PMid:26974354.

Minato, K. I., Ohara, A., \& Mizuno, M. (2017). A Proinflammatory Effect of the b-Glucan from Pleurotus cornucopiae mushroom on 
macrophage action. Mediators of Inflammation, 2017, 8402405. http://dx.doi.org/10.1155/2017/8402405. PMid:28611507.

Munkácsy, G., Abdul-Ghani, R., Mihály, Z., Tegze, B., \& Györffy, B. (2010). Psmb7 is associated with anthracycline resistance and is a prognostic biomarker in breast cancer. British Journal of Cancer, 102(361), 361-368. PMid:20010949.

Park, H., Li, Z., Yang, X. O., Chang, S. H., Nurieva, R., Wang, Y.-H., Wang, Y., Hood, L., Zhu, Z., Tian, Q., \& Dong, C. (2005). A distinct lineage of $\mathrm{cd} 4 \mathrm{t}$ cells regulates tissue inflammation by producing interleukin 17. Nature Immunology, 6(11), 1133-1141. http://dx.doi. org/10.1038/ni1261. PMid:16200068.

Pitceathly, R. D. S., Murphy, S. M., Cottenie, E., Chalasani, A., Sweeney, M. G., Woodward, C., Mudanohwo, E. E., Hargreaves, I., Heales, S., Holton, J. L., Houlden, H., Lunn, M. P., Rahman, S., Reilly, M. M., \& Hanna, M. G. (2012). P50 genetic dysfunction of mt-atp6 can cause axonal charcot-marie-tooth disease. Neuromuscular Disorders, 22, S20. http://dx.doi.org/10.1016/S0960-8966(12)70058-5.

Shema, R., Sacktor, T. C., \& Dudai, Y. (2007). Rapid erasure of long-term memory associations in the cortex by an inhibitor of pkm $\zeta$. Science, 317(5840), 951-953. http://dx.doi.org/10.1126/science.1144334. PMid:17702943.

Sun, H., Chen, W., Jiang, Y., He, Q., Li, X., Guo, Q., Xiang, S., Xi, W., \& Liang, G. (2020). Characterization of volatiles in red- and whitefleshed loquat (Eriobotrya japonica) fruits by electronic nose and headspace solid-phase microextraction with gas chromatographymass spectrometry. Food Science and Technology, 40(Suppl. 1), 21-32. http://dx.doi.org/10.1590/fst.27318.

Tabebi, M., Mkaouar-Rebai, E., Mnif, M., Kallabi, F., Mahmoud, A. B., Saad, W. B., Charfi, N., Keskes-Ammar, L., Kamoun, H., Abid, M., \& Fakhfakh F. (2015). A novel mutation mt-coiii m.9267g $>c$ and mt-coi m.5913g $>$ a mutation in mitochondrial genes in a tunisian family with maternally inherited diabetes and deafness (midd) associated with sever nephropathy. Biochemical and Biophysical
Research Communications, 459(3), 353-360. http://dx.doi.org/10.1016/j. bbrc.2015.01.151. PMid:25701779.

Valverde, M. E., Hernández-Pérez, T., \& Paredes-López, O. (2015). Edible mushrooms: Improving human health and promoting quality Life. International Journal of Microbiology, 2015, 376387 http://dx.doi. org/10.1155/2015/376387. PMid:25685150.

Wang, S. J., Bao, L., Han, J. J., Wang, Q. X., Yang, X. L., Wen, H. A., Guo, L. D., Li, S. J., Zhao, F., \& Liu, H. W. (2013). Pleurospiroketals A-E, perhydrobenzannulated 5,5-spiroketal sesquiterpenes from the edible mushroom Pleurotus cornucopiae. Journal of Natural Products, 76(1), 45-50. http://dx.doi.org/10.1021/np3006524. PMid:23294419.

Whillock, A. L., Ybarra, T. K., \& Bishop, G. A. (2021). Tnf receptorassociated factor 3 restrains b cell receptor signaling in normal and malignant B cells. The Journal of Biological Chemistry, 296, 100465. http://dx.doi.org/10.1016/j.jbc.2021.100465. PMid:33639170.

Wu, X., Huang, C., Chen, Q., Wang, H., \& Zhang, J. (2014). A novel laccase with inhibitory activity towards HIV-I reverse transcriptase and antiproliferative effects on tumor cells from the fermentation broth of mushroom Pleurotus cornucopiae. Biomedical Chromatography, 28(4), 548-553. http://dx.doi.org/10.1002/bmc.3068. PMid:24136666.

Yang, F., Wang, Y., \& Zhao, H. (2020). Quality enhancement of fermented vegetable juice by probiotic through fermented yam juice using Saccharomyces cerevisiae. Food Science and Technology, 40(1), 2635. http://dx.doi.org/10.1590/fst.29918.

Zhang, J., Ma, Z., Zheng, L., Zhai, G., Wang, L., Jia, M., \& Jia, L. (2014). Purification and antioxidant activities of intracellular zinc polysaccharides from Pleurotus cornucopiae SS-03. Carbohydrate Polymers, 111, 947-954. http://dx.doi.org/10.1016/j.carbpol.2014.04.074. PMid:25037435.

Zheng, H., Chen, J., Weng, M., Ahmad, I., \& Zhou, C. (2020). Structural characterization and bioactivities of a polysaccharide from the stalk residue of Pleurotus eryngii. Food Science and Technology, 40(Suppl. 1), 235-241. http://dx.doi.org/10.1590/fst.08619. 